Published in final edited form as:

Eur J Cancer Prev. 2016 May ; 25(3): 173-181. doi:10.1097/CEJ.0000000000000160.

\title{
Association of serum cytokines with colorectal polyp number and type in adult males
}

\author{
Sarah S. Comstock ${ }^{1}$, Diana Xu ${ }^{1}$, Kari Hortos ${ }^{2}$, Bruce Kovan ${ }^{2,3}$, Sarah McCaskey ${ }^{2}$, Dorothy \\ R. Pathak ${ }^{4}$, and Jenifer I. Fenton ${ }^{1,2,{ }^{*}}$ \\ 1 \\ 2 \\ 3 \\ 4
}

\section{Abstract}

Chronic inflammation contributes to colorectal carcinogenesis. To determine if serum cytokines are associated with colon polyps, 126 asymptomatic men (48-65yr) were recruited at colonoscopy. Serum cytokine concentrations were measured. Odds ratios were determined using polytomous logistic regression for polyp number and type. Males with serum monocyte chemotactic protein-3 (MCP-3) or soluble interleukin-4 receptor (sIL-4R) concentrations in the highest tertile were 0.2 times less likely to have $\geq 3$ polyps relative to no polyps. For each increase in serum MCP-3 or sIL-4R tertile a man was about 0.4 times less likely to have $\geq 3$ polyps than no polyps. Males with serum concentrations of interferon-a2 (IFN-a2) or interleukin (IL)-7 in the highest tertile were 3 times more likely to have an adenoma relative to no polyps. Those with serum IL-8 concentrations in the highest tertile were 4 times more likely to have an adenoma relative to no polyps. For each increase in serum IFN-a2, IL-7 or IL-8 tertile an individual was 1.8 times more likely to have an adenoma than no polyp. Serum concentrations of MCP-3, sIL-4R, IFN-a2, IL-7 and IL-8 may indicate which men are more likely to have colorectal polyps.

\section{Keywords}

colon; colorectal; polyp; adenoma; cytokines; colonoscopy; prevention; males; biomarker; human

\section{Introduction}

Colonoscopy is known to be highly effective at preventing cases of colorectal cancer (Zauber et al., 2012). However, many individuals are reluctant to be screened in this manner (Mclachlan et al., 2012), and the procedure is costly (Rosenthal, 2013; Sinsky and Dugdale, 2013). Methods to identify which individuals would benefit most from colonoscopy are

*Corresponding Author: Jenifer I. Fenton, 208B G.M. Trout Bldg, Michigan State University, East Lansing, MI, USA, 48824. imigjeni@msu.edu. Phone: 517-353-3342..

Conflicts of interest: none declared. 
needed. One such method may be the use of serum factors to predict individuals at highest risk for the presence of colorectal polyps.

Inflammation is a critical component of cancer initiation and progression (Hanahan and Weinberg, 2011). Initial chronic inflammation can activate cellular functions that induce irreversible DNA damage and increase the risk of cancer (Grivennikov et al., 2010). However, the immune system also responds to already mutated cells, and chronic inflammation may result from an inability of the immune system to kill and clear those cells. Typically it is the local epithelial cells or innate immune cells such as neutrophils, monocytes/macrophages and dendritic cells, which are responsible for these actions. These cell types synthesize cytokines such as monocyte chemoattractant protein (MCP)-3, macrophage derived chemokine (MDC), interferon-alpha2 (IFN-a2), interleukin(IL)-7 and IL-8. When these proteins are produced in high quantities locally, they can diffuse from the tissue and be detected in the blood.

Because inflammation is commonly linked to cancer initiation as well as progression (Elinav et al., 2013), serum cytokines levels are likely to be useful predictive biomarkers of colorectal polyp formation and risk for future colorectal cancer. In fact, a recent study successfully identified a prognostic classifier for colorectal metastasis using serum concentrations of 17 cytokines (Chen et al., 2014). Another study demonstrated that colorectal dysplasia was positively associated with local intestinal inflammation and inversely associated with immune therapy (Rubin et al., 2013). However, few studies have attempted to identify serum cytokines associated with colorectal polyps. This study investigated potential associations between serum cytokine levels and colorectal polyp number or type in a population of adult males undergoing preventative screening colonoscopy.

\section{Materials and Methods}

\section{Study Population}

Between August 2009 and February 2011, healthy males ranging from 48-65 years of age were recruited from MSU-affiliated clinics, either Tri-County Gastroenterology Clinic (Macomb, MI) or Michigan State University Clinic (East Lansing, MI), at the time of colonoscopy. These individuals were undergoing routine colonoscopies and were asymptomatic. Exclusion criteria included: 1) cancer within the past two years, 2) surgery within the past two years, 3) inflammatory bowel diseases (i.e. Crohn's, ulcerative colitis), 4) autoimmune disorders (i.e. Rheumatoid arthritis, HIV/AIDS, Lupus), 5) type I or type II diabetes, 6) chronic liver or kidney disease, 7) history of heart failure, 8) current immunosuppressant usage (i.e. Prednisone), 9) asthma, chronic obstructive pulmonary disease or other lung problems, 10) familial adenomatous polyposis, and 11) Lynch syndrome or hereditary non-polyposis colorectal cancer. 126 men ( >96\% Caucasian) participated in the study (Table 1). At the time of enrollment, immediately prior to routine colonoscopy, written informed consent was obtained and clinical metadata on subject comorbidities, current medications, and family history were collected. Anthropometric measures were taken to calculate BMI and to record waist circumference (Comstock et al., 2014a). Also at the time of enrollment, venous blood was drawn, and serum was isolated by 
standard procedures and stored at $-80^{\circ} \mathrm{C}$. The study was approved by the institutional review board of Michigan State University (IRB\# 08-786).

\section{Colonoscopy Interpretation}

Full colonoscopy was performed on each participant. A gastroenterologist (MSU-affiliated clinics, MI) categorized the location of each polyp during the colonoscopy. Board-certified pathologists assigned a polyp type to each specimen collected during colonoscopy (regional medical center pathology departments).

\section{Serum Biomarker Analysis}

Serum concentrations of the soluble interleukin-4 receptor (sIL-4R), soluble CD30 (sCD30), soluble gp130 (sgp130), and the soluble interleukin-2 receptor (sIL-2Ra) were determined using a multiplex kit for soluble cytokine receptors (HSCR-32K, Millipore) as per the manufacturer's instructions. Further, IFN-a2, IL-7, IL-8, MCP-3, eotaxin, fms-like tyrosine kinase-3 ligand (FLT-3L), fractalkine, granulocyte-colony stimulating factor (G-CSF), granulocyte macrophage-colony stimulating factor (GM-CSF), GRO1 oncogene (CXCL1/ GRO), interferon-gamma (IFN- $\gamma$ ), IL-15, transforming growth factor-alpha (TGF- $\alpha$ ), IL-3, IL-4, IL-5, IL-9, IL-13 and MDC serum concentrations were measured using a multiplex human cytokine/chemokine kit (MPXHCYTO-60K, Millipore). Multiplex assays were analyzed on a Bio-Plex 100 using Bio-Plex 4.1 software (Bio-Rad, Hercules, CA).

\section{Statistical Analyses}

Frequencies, means, standard deviations and ranges were calculated for descriptive analysis. Because the serum cytokine concentrations were non-normally distributed, Spearman correlations are presented (Table 3). All of the cytokine and soluble receptors were categorized into tertiles for polytomous logistic regression analysis. Biological cut off points were used for the outcome variables: polyp number and polyp type. Polyp number was set to four categories: $0,1,2$, or $\geq 3$ polyps. Polyp type was set to three categories: no polyps, hyperplastic polyp(s) or tubular adenoma(s). For polyp type, each individual was assigned a single score based on the colorectal polyp with the worst pathology.

Each individual was assigned a smoking status of "never smoked" or "ever smoked". An individual was classified as "never smoked" if he had smoked fewer than 100 cigarettes over the course of his lifetime. Smoking status was missing for 22 individuals (17.5\% missingness). All missing data were considered missing at random.

Multiple imputation (seed $=20121119$, imputations $=7$ ) was used to impute all missing smoking data and the one participant's value missing for the factors measured with the multiplex human cytokine/chemokine kit (Yuan, 2011). The factors: age, smoking, polyp type, polyp number and the factor being imputed were used in the imputation algorithm of missing values (Moons et al., 2006).

Odds ratios (OR) were determined using polytomous logistic regression models for categorical outcome data with more than two levels. A generalized logit model (also known as a, "baseline category logit model") formed the basis of the polytomous logistic regression 
model for our analyses. In this model, men having $\geq 3$ polyps, 2 polyps or 1 polyp were compared to men having no polyps. Results were obtained for each serum factor categorized into tertiles (with lowest tertile as reference) for each category of polyp number or polyp type relative to no polyp. For clarity, only results from the categories featuring the most polyps ( 33 ) and the polyp type most likely to progress to colorectal cancer (adenoma) are presented. For dichotomous outcomes odds ratios were determined using logistic regression. All models were adjusted for age and smoking status. Test for trend was carried out across tertiles for the factors of interest. Because imputation was used, multiple imputation analyze (Proc MIANALYZE) was used to determine the results from analysis of the imputed data sets. SAS version 9.3 (SAS Institute Inc.; Cary, NC) was used for all statistical analysis. p s 0.05 indicates significance.

\section{Results}

Some details about this study population have recently been published (Comstock et al., 2014a; Comstock et al., 2014b; Comstock et al., 2014c). Briefly (Table 1), 57 (45\%) of the 126 participants had at least one polyp. Remaining participants had no polyps. 37 (29.4\%) of the participants had a tubular adenoma. Furthermore, 17 of the $23(18 \%)$ participants with $\geq$ 3 polyps had at least one tubular adenoma.

No associations between polyp number or polyp type were found for the following factors: eotaxin, FLT-3L, fractalkine, G-CSF, GM-CSF, GRO, IFN- $\gamma$, IL-15, TGF- $a$, sCD30, sgp130, sIL-2Ra, IL-3, IL-4, IL-5, IL-9, or IL-13. Only serum concentrations of MDC were associated with the presence of hyperplastic polyps. There were no individual effects among MDC tertiles, but there was a 2.2 fold increase in odds (CI, 1.1-4.4) of having a hyperplastic polyp compared to having no polyp for each increase in the tertile of MDC serum concentration $(\mathrm{p}=0.0227)$.

Concentrations of cytokines and soluble receptors significantly associated with either polyp number or type are presented in Table 2. These serum factors correlated with each other as well as with participant characteristics (Table 3). Only one factor was significantly correlated with age. The sIL-4R was inversely correlated with age. Multiple cytokines including IFN-a2, IL-7, IL-8, IL-10 and MDC positively correlated with BMI. All of these serum cytokines, except IL-10, also positively correlated with waist circumference. Neither BMI nor waist circumference correlated with serum sIL-4R concentrations. With few exceptions, serum cytokine levels were positively correlated with each other. Notably, serum MDC concentration was not correlated with serum IL-10 or MCP-3 concentrations and tended to be negatively correlated with serum sIL-4R concentrations. Neither IFN-a2 nor IL-8 correlated with sIL-4R serum concentrations.

High serum concentrations of MCP- 3 and sIL- $4 \mathrm{R}$ reduced the odds that a participant would have $\geq 3$ polyps. Compared to males with a serum MCP- 3 concentration $\leq 7.16 \mathrm{pg} / \mathrm{ml}$, males with a serum MCP-3 concentration $>15.98 \mathrm{pg} / \mathrm{ml}$ were 0.21 times less likely to have $\geq 3$ polyps $(\mathrm{p}=0.0196)$ relative to no polyps (Figure 1A). In addition for each increase in serum MCP-3 tertile, a man was 0.44 times less likely to have $\geq 3$ polyps than no polyps ( $\mathrm{p}=0.0126$ ). When compared to males with a serum sIL-4R concentration $\leq 1360.0 \mathrm{pg} / \mathrm{ml}$, 
males with a serum sIL-4R concentration $>1575.0 \mathrm{pg} / \mathrm{ml}$ were 0.22 times less likely to have $\geq 3$ polyps ( $\mathrm{p}=0.0246$ ) relative to no polyps (Figure 1B). For each increase in serum sIL-4R tertile, a man was 0.45 times less likely to have $\geq 3$ polyps than no polyps ( $\mathrm{p}=0.0180$ ). Conversely high serum levels of MDC tended to increase the odds that a participant would have $\geq 3$ polyps compared to no polyps (Table 4). Serum concentrations of IFN-a2, IL-7, IL-8 and IL-10 were not associated with polyp number.

Concentrations of several serum cytokines were associated with the presence of a colorectal adenoma (Table 5). Males with a serum IFN-c2 concentration $>33.12 \mathrm{pg} / \mathrm{ml}$ were 2.8 times more likely than males with a serum IFN-a2 concentration $\leq 14.98 \mathrm{pg} / \mathrm{ml}$ to have an adenoma ( $\mathrm{p}=0.0468$ ) relative to no polyps (Figure 2A). As the tertile of serum IFN- $\mathrm{a} 2$ increased an individual was 1.75 times more likely to have an adenoma than no polyp $(\mathrm{p}=0.0391)$. When compared to males with a serum IL-7 concentration $\leq 3.54 \mathrm{pg} / \mathrm{ml}$, males with a serum IL-7 concentration $>12.06 \mathrm{pg} / \mathrm{ml}$ were 3.3 times more likely to have an adenoma ( $\mathrm{p}=0.0277$ ) relative to no polyps (Figure 2B). As the serum IL-7 tertile increased an individual was 1.82 times more likely to have an adenoma than no polyp ( $\mathrm{p}=0.0288$ ). Compared to males with a serum IL-8 concentration $\leq 6.76 \mathrm{pg} / \mathrm{ml}$, males with a serum IL-8 concentration $>10.74 \mathrm{pg} / \mathrm{ml}$ were 4.0 times more likely to have an adenoma $(\mathrm{p}=0.0158)$ relative to no polyps (Figure 2C). Further, for each increase in serum IL-8 tertile, an individual was 1.85 times more likely to have an adenoma than no polyp ( $\mathrm{p}=0.0213$ ). High serum concentrations of IL-10 tended to be positively associated with the presence of an adenoma (Table 5). However, high serum concentrations of sIL-4R tended to be negatively associated with the presence of an adenoma. The serum concentrations of MCP-3 and MDC were not associated with the presence of an adenoma.

\section{Discussion}

Recent studies have evaluated the relationship between serum cytokines and colorectal cancer, yet few have comprehensively analyzed the relationship between serum cytokine concentrations and colorectal polyps (Bunger et al., 2012; Kang et al., 2013). In this study, serum concentrations of the cytokines MCP-3, sIL-4R, IFN-a2, IL-7 and IL-8 were associated with polyp number or type in asymptomatic adult males. Specifically, high levels of MCP-3 or sIL-4R were associated with decreased odds of having $\geq 3$ polyps. Whereas, high levels of IFN-a2, IL-7 and IL-8 were associated with increased odds of having a colorectal adenoma. Many other serum cytokines, including eotaxin, G-CSF, GM-CSF, GRO1, IFN- $\gamma$ and IL-5, were not associated with either polyp number or the presence of a colorectal adenoma.

Most studies of colorectal polyps focused on select markers of inflammation, most commonly IL-6, TNF-a and c-reactive protein (CRP) (Hopkins et al., 2012; Il'yasova et al., 2005; Kim et al., 2008; Wild et al., 2010). These studies found IL-6, TNF-a, and CRP as well as non-cytokine markers, such as carcinoembryonic antigen and ferritin, are positively associated with the presence of colorectal adenomas as well as with general cancer incidence. As we have previously published, although IL-6 was not associated, TNF- $a$ was significantly associated with the presence of colorectal adenomas in our study population (Comstock et al., 2014a). We did not measure CRP concentrations. Notably, some of the 
serum expression patterns identified herein are consistent with findings in studies of colorectal polyps and colorectal carcinomas. Of the studies evaluating large sets of cytokines, TNF- $a$ and IL-8 were associated with polyps (Bunger et al., 2012; Kang et al., 2013). We also identified associations between TNF-a (Comstock et al., 2014a) and IL-8 with polyps. In a report by Chen et al (Chen et al., 2014), IFN-a2, IL-10, MCP-3, MDC, IL-7, IL-8, tumor necrosis factor (TNF)-a, interferon-gamma-induced protein (IP)-10 and vascular endothelial growth factor (VEGF) were associated with metastatic colorectal cancer. IL-8, IP-10 and TNF-a were also positively associated with the presence of colorectal carcinoma in a separate population (Choi et al., 2013). Our study identified associations of IFN-a2, IL-10, MCP-3, MDC, IL-7 and IL-8 with colorectal polyps. Additionally, TNF-a, IP-10 and VEGF have been previously reported to be associated with colorectal polyps in this population (Comstock et al., 2014a; Comstock et al., 2014c). Therefore, data from the current study population supports that of other studies analyzing serum cytokines in cases of colorectal neoplasia. Furthermore, it expands previous knowledge by demonstrating that these serum cytokine levels are modified even in the early stages of colon cancer initiation.

Cytokines are important for cancer progression. They affect apoptosis, proliferation, angiogenesis and mutagenesis. Most frequently these functions are accomplished by signaling through molecules such as nuclear factor-kappa B (NF-kB), cyclooxygenase-2 (COX-2) or signal tranducer and activator of transcription 3 (STAT3) (Dreesen and Brivanlou, 2007; Grivennikov and Karin, 2010; Parsons et al., 2005). For instance, STAT3 activation is pivotal in tumorigenesis (reviewed in (Coussens et al., 2013; Fan et al., 2013)). Several of the cytokines positively associated with increased numbers of polyps or the presence of an adenoma including IFN-a2 (Raz et al., 1994), IL-7 (Qin et al., 2001), and IL-10 (Finbloom and Winestock, 1995) signal through STAT3. Additionally, IL-4 signals through STAT3 (Rolling et al., 1996), and herein the soluble IL-4R was inversely associated with having $\geq 3$ polyps as well as tending to be inversely associated with the presence of a tubular adenoma indicating that STAT3 signaling may be inhibited under conditions of high sIL-4R. Serum leptin, which also activates STAT3 (Bjorbaek et al., 1997), was previously positively associated with increased odds of having $>3$ polyps as well as increased odds of having a tubular adenoma (Comstock et al., 2014a).

Serum levels of IL-8, an angiogenic protein that is also known as CXCL8, were positively associated with the odds of having an adenoma compared to no polyp. Macrophages, endothelial cells and tumors produce IL- 8 drawing granulocytes and activating neutrophils to the local environment. IL-8 induces VEGF expression leading to angiogenesis (Kotyza, 2012; Singh et al., 2010; Todorovic-Rakovic and Milovanovic, 2013). This chemokine also stimulates tumor cell invasiveness and cancer progression (Fernando et al., 2011; Palena et al., 2012; Todorovic-Rakovic and Milovanovic, 2013; Waugh and Wilson, 2008). In a study of colorectal tissue, IL-8 mRNA and protein was more highly expressed in samples from colorectal tumors compared to those isolated from areas of inflammatory colorectal conditions or adenomas of the colon/rectum (Rubie et al., 2007). In combination with the fact that serum IL-8 levels were associated with colorectal carcinoma and polyps, these results suggest that increased IL-8, both locally and systemically, is important in the development of colorectal polyps as well as colorectal cancer. 
Inflammatory cytokines also activate proliferative responses during cancer initiation steps. In this study, levels of IL-7 were positively associated with the presence of an adenoma. This is potentially related to the ability of this cytokine to promote proliferation of a variety of cell types (Namen et al., 1988; Vollger and Uittenbogaart, 1993). It may do this through STAT signaling (Van Der Plas et al., 1996) as well as through activation of phosphoinositide-3-kinase (PI3K) (Dadi and Roifman, 1993). Furthermore, IL-7 can stimulate production of other inflammatory cytokines (Appasamy, 1993).

The immune system can inhibit as well as enhance the tumorigenicity of pre-cancerous or cancerous cells (Chow et al., 2012). Two serum proteins, MCP-3 and sIL-4R, inversely associated with colorectal polyps in the present analysis likely contribute cytotoxic skewing effects. MCP-3, also known as CCL7, recruits and activates most types of immune cells, including NK cells (Alam et al., 1994; Allavena et al., 1994; Loetscher et al., 1996; Noso et al., 1994; Sozzani et al., 1994; Taub et al., 1995; Uguccioni et al., 1995; Xu et al., 1995). In fact, MCP-3 stimulates tumor regression (Fioretti et al., 1998; Wetzel et al., 2001), and herein high serum MCP-3 levels were associated with a decreased odds of having $\geq 3$ polyps compared to having no polyps demonstrating that MCP-3 can be protective at high serum concentrations. Additionally, serum sIL-4R was negatively associated with the odds of having $\geq 3$ polyps compared to no polyps and tended to be negatively associated with the odds of having an adenoma compared to no polyps. These associations are likely due to the inhibitory effect of this soluble cytokine receptor on IL-4 signaling. Through inhibition of IL-4, sIL-4R creates an environment more conducive to polyp/tumor regression. Anti-IL-4 therapeutic antibodies have been demonstrated to reprogram tumor-associated macrophages, monocytes and other cells toward cytotoxic phenotypes in mammary cancer (Denardo et al., 2009). Thus, the inverse relationship between serum MCP-3 and sIL-4R and colorectal polyp number could potentially be due to their cytotoxic skewing effects.

On the other hand, cytokines, such as IL-10, which are typically regulatory (O'garra and Vieira, 2007) are elevated in cancer (Mustea et al., 2006; Sato et al., 1996). Some IL-10 polymorphisms are associated with cancer (Howell and Rose-Zerilli, 2006). In the current study population, serum IL-10 tended to be positively associated with having an adenoma compared to no polyp. MDC, also known as CCL22, is associated with tumor promotion because it attracts regulatory $\mathrm{T}$ cells to the tumor site (Faget et al., 2011). The presence of these regulatory $\mathrm{T}$ cells inhibits other immune cells, specifically cytotoxic immune cells. The positive relationship trends between IL-10 and polyp type as well as between MDC and polyp number could potentially be due to their anti-cytotoxic skewing effects. The time during polyp formation and progression determines disease trajectory. Inflammation and the immune system are important throughout tumor development, from initiation to metastasis, but many of the specifics are unknown (Coussens et al., 2013; Fan et al., 2013). The association of specific serum cytokine concentrations with the presence of colorectal polyps supports the hypothesis that serum cytokines likely play a role in colorectal cancer initiation and progression. However, our results do not address the effects of changes in serum cytokines with progression because we only analyzed one point in time for each participant and did not analyze the associations of cytokine combinations with polyp number or the presence of adenoma. Different cytokines were inversely associated with polyp number (MCP-3, sIL-4R) than were positively associated with the presence of an adenoma (IFN-a2, 
IL-7, IL-8) suggesting that initiation may rely on a cytotoxic or damaging environment while progression may rely on factors that promote angiogenesis and proliferation.

Strengths of the present study include the design. The study was cross-sectional with consecutive enrollment resulting in reduced enrollment bias. Additionally, only asymptomatic individuals undergoing a complete screening were enrolled, and individuals immediately participated in the study removing potential bias from loss to follow-up. We selected for healthy individuals lacking conditions known to be related to underlying inflammation to avoid detection of un-related inflammatory signals. Trained staff measured body weight and height so there was no reliance on self-report. The scope of information collected from participants about relevant confounding variables enabled factors such as smoking history to be controlled for in the analysis. Therefore, the results of this study are likely typical for men of an ethnicity and age similar to that of this well-defined study population.

However, caution must be used when interpreting the results of this study because the study had some limitations. For instance, the results may not apply to individuals of other ethnicities or females since this study was conducted in a sample of primarily Caucasian, adult males. Some data was imputed. However, these few imputations likely have minimal effects on the overall results. The associations described in this study were based on crosssectional data thus cause cannot be assigned to any factors identified as associated with polyp number or type. Only a single time point is analyzed, but effects of cytokines on polyp formation may be related to the duration and localization of exposure. Local production is difficult to measure, and serum measurements are more useful in a clinical setting. Furthermore, although we did not detect associations between a number of cytokines with polyp number or the presence of an adenoma, this could be due to the sample size or specific characteristics of the population rather than the result of a lack of association in all circumstances. In summary, the results of this study should be verified using a larger, more representative sample size.

Further examination of the serum factors identified in this study as they relate to polyp formation and progression could elucidate pathways by which the immune system successfully prevents cancer or, alternatively, contributes to cancer. Additionally, although the identified factors may also be elevated in the serum of individuals with other tumor types, the association of specific serum cytokine concentrations with the presence of colorectal polyps suggests that these serum factors could potentially predict which individuals are likely to have polyps and therefore benefit from colonoscopy screening.

\section{Acknowledgements}

We thank the Michigan State University Center for Statistical Training and Consulting, specifically, our consultant, David Reyes-Gastelum for valuable insight into methods of multiple imputation. We thank Lori Houghton-Rahrig for IRB protocol and standard operating procedure preparation assistance and training of support staff. We thank Dr. Sharon Hoerr for providing anthropometric measurement consultation, initial training, and training tools.

Research supported in part by the National Cancer Institute 1R03CA142000 and the Clinical and Translational Sciences Institute at Michigan State University. 


\section{References}

Alam R, Forsythe P, Stafford S, Heinrich J, Bravo R, Proost P, et al. Monocyte chemotactic protein-2, monocyte chemotactic protein-3, and fibroblast-induced cytokine. Three new chemokines induce chemotaxis and activation of basophils. J Immunol. 1994; 153:3155-3159. [PubMed: 7522251]

Allavena P, Bianchi G, Zhou D, van Damme J, Jilek P, Sozzani S, et al. Induction of natural killer cell migration by monocyte chemotactic protein-1, -2 and -3. Eur J Immunol. 1994; 24:3233-3236. [PubMed: 7805752]

Appasamy PM. Interleukin-7: Biology and potential clinical applications. Cancer Invest. 1993; 11:487-499. [PubMed: 8324652]

Bjorbaek C, Uotani S, da Silva B, Flier JS. Divergent signaling capacities of the long and short isoforms of the leptin receptor. J Biol Chem. 1997; 272:32686-32695. [PubMed: 9405487]

Bunger S, Haug U, Kelly M, Posorski N, Klempt-Giessing K, Cartwright A, et al. A novel multiplexprotein array for serum diagnostics of colon cancer: A case-control study. BMC Cancer. 2012; 12:393. [PubMed: 22954206]

Chen ZY, He WZ, Peng LX, Jia WH, Guo RP, Xia LP, et al. A prognostic classifier consisting of 17 circulating cytokines is a novel predictor of overall survival for metastatic colorectal cancer patients. Int J Cancer. 2014; 136:584-592. [PubMed: 24916890]

Choi JW, Liu H, Shin DH, Yu GI, Hwang JS, Kim ES, et al. Proteomic and cytokine plasma biomarkers for predicting progression from colorectal adenoma to carcinoma in human patients. Proteomics. 2013; 13:2361-2374. [PubMed: 23606366]

Chow MT, Moller A, Smyth MJ. Inflammation and immune surveillance in cancer. Semin Cancer Biol. 2012; 22:23-32. [PubMed: 22210181]

Comstock SS, Hortos K, Kovan B, McCaskey S, Pathak DR, Fenton JI. Adipokines and obesity are associated with colorectal polyps in adult males: A cross-sectional study. PLoS One. 2014a; 9:e85939. [PubMed: 24465801]

Comstock SS, Lewis MM, Pathak DR, Hortos K, Kovan B, Fenton JI. Cross-sectional analysis of obesity and serum analytes in males identifies srage as a novel biomarker inversely associated with diverticulosis. PLoS One. 2014b; 9:e95232. [PubMed: 24740401]

Comstock SS, Xu D, Hortos K, Kovan B, McCaskey S, Pathak DR, et al. Association of insulinrelated serum factors with colorectal polyp number and type in adult males. Cancer Epidemiol Biomarkers Prev. 2014c; 23:1843-1851. [PubMed: 24962837]

Coussens LM, Zitvogel L, Palucka AK. Neutralizing tumor-promoting chronic inflammation: A magic bullet? Science. 2013; 339:286-291. [PubMed: 23329041]

Dadi HK, Roifman CM. Activation of phosphatidylinositol-3 kinase by ligation of the interleukin-7 receptor on human thymocytes. J Clin Invest. 1993; 92:1559-1563. [PubMed: 8397227]

DeNardo DG, Barreto JB, Andreu P, Vasquez L, Tawfik D, Kolhatkar N, et al. Cd4(+) t cells regulate pulmonary metastasis of mammary carcinomas by enhancing protumor properties of macrophages. Cancer Cell. 2009; 16:91-102. [PubMed: 19647220]

Dreesen O, Brivanlou AH. Signaling pathways in cancer and embryonic stem cells. Stem Cell Rev. 2007; 3:7-17. [PubMed: 17873377]

Elinav E, Nowarski R, Thaiss CA, Hu B, Jin C, Flavell RA. Inflammation-induced cancer: Crosstalk between tumours, immune cells and microorganisms. Nat Rev Cancer. 2013; 13:759-771. [PubMed: 24154716]

Faget J, Biota C, Bachelot T, Gobert M, Treilleux I, Goutagny N, et al. Early detection of tumor cells by innate immune cells leads to $\mathrm{t}(\mathrm{reg})$ recruitment through $\mathrm{ccl} 22$ production by tumor cells. Cancer Res. 2011; 71:6143-6152. [PubMed: 21852386]

Fan Y, Mao R, Yang J. Nf-kappab and stat3 signaling pathways collaboratively link inflammation to cancer. Protein Cell. 2013; 4:176-185. [PubMed: 23483479]

Fernando RI, Castillo MD, Litzinger M, Hamilton DH, Palena C. Il-8 signaling plays a critical role in the epithelial-mesenchymal transition of human carcinoma cells. Cancer Res. 2011; 71:52965306. [PubMed: 21653678] 
Finbloom DS, Winestock KD. Il-10 induces the tyrosine phosphorylation of tyk2 and jak1 and the differential assembly of stat 1 alpha and stat 3 complexes in human t cells and monocytes. $\mathbf{J}$ Immunol. 1995; 155:1079-1090. [PubMed: 7543512]

Fioretti F, Fradelizi D, Stoppacciaro A, Ramponi S, Ruco L, Minty A, et al. Reduced tumorigenicity and augmented leukocyte infiltration after monocyte chemotactic protein-3 (mcp-3) gene transfer: Perivascular accumulation of dendritic cells in peritumoral tissue and neutrophil recruitment within the tumor. J Immunol. 1998; 161:342-346. [PubMed: 9647242]

Grivennikov SI, Greten FR, Karin M. Immunity, inflammation, and cancer. Cell. 2010; 140:883-899. [PubMed: 20303878]

Grivennikov SI, Karin M. Dangerous liaisons: Stat3 and nf-kappab collaboration and crosstalk in cancer. Cytokine Growth Factor Rev. 2010; 21:11-19. [PubMed: 20018552]

Hanahan D, Weinberg RA. Hallmarks of cancer: The next generation. Cell. 2011; 144:646-674. [PubMed: 21376230]

Hopkins MH, Flanders WD, Bostick RM. Associations of circulating inflammatory biomarkers with risk factors for colorectal cancer in colorectal adenoma patients. Biomark Insights. 2012; 7:143150. [PubMed: 23170065]

Howell WM, Rose-Zerilli MJ. Interleukin-10 polymorphisms, cancer susceptibility and prognosis. Fam Cancer. 2006; 5:143-149. [PubMed: 16736283]

Il'yasova D, Colbert LH, Harris TB, Newman AB, Bauer DC, Satterfield S, et al. Circulating levels of inflammatory markers and cancer risk in the health aging and body composition cohort. Cancer Epidemiol Biomarkers Prev. 2005; 14:2413-2418. [PubMed: 16214925]

Kang M, Edmundson P, Araujo-Perez F, McCoy AN, Galanko J, Keku TO. Association of plasma endotoxin, inflammatory cytokines and risk of colorectal adenomas. BMC Cancer. 2013; 13:91. [PubMed: 23442743]

Kim S, Keku TO, Martin C, Galanko J, Woosley JT, Schroeder JC, et al. Circulating levels of inflammatory cytokines and risk of colorectal adenomas. Cancer Res. 2008; 68:323-328. [PubMed: 18172326]

Kotyza J. Interleukin-8 (cxc18) in tumor associated non-vascular extracellular fluids: Its diagnostic and prognostic values. A review. Int J Biol Markers. 2012; 27:169-178. [PubMed: 22610755]

Loetscher P, Seitz M, Clark-Lewis I, Baggiolini M, Moser B. Activation of nk cells by cc chemokines. Chemotaxis, ca2+ mobilization, and enzyme release. J Immunol. 1996; 156:322-327. [PubMed: 8598480]

McLachlan SA, Clements A, Austoker J. Patients' experiences and reported barriers to colonoscopy in the screening context--a systematic review of the literature. Patient Educ Couns. 2012; 86:137146. [PubMed: 21640543]

Moons KG, Donders RA, Stijnen T, Harrell FE Jr. Using the outcome for imputation of missing predictor values was preferred. J Clin Epidemiol. 2006; 59:1092-1101. [PubMed: 16980150]

Mustea A, Konsgen D, Braicu EI, Pirvulescu C, Sun P, Sofroni D, et al. Expression of il-10 in patients with ovarian carcinoma. Anticancer Res. 2006; 26:1715-1718. [PubMed: 16617566]

Namen AE, Schmierer AE, March CJ, Overell RW, Park LS, Urdal DL, et al. B cell precursor growthpromoting activity. Purification and characterization of a growth factor active on lymphocyte precursors. J Exp Med. 1988; 167:988-1002. [PubMed: 3258354]

Noso N, Proost P, Van Damme J, Schroder JM. Human monocyte chemotactic proteins-2 and 3 (mcp-2 and mcp-3) attract human eosinophils and desensitize the chemotactic responses towards rantes. Biochem Biophys Res Commun. 1994; 200:1470-1476. [PubMed: 7514401]

O'Garra A, Vieira P. T(h)1 cells control themselves by producing interleukin-10. Nat Rev Immunol. 2007; 7:425-428. [PubMed: 17525751]

Palena C, Hamilton DH, Fernando RI. Influence of il-8 on the epithelial mesenchymal transition and the tumor microenvironment. Future Oncol. 2012; 8:713-722. [PubMed: 22764769]

Parsons DW, Wang TL, Samuels Y, Bardelli A, Cummins JM, DeLong L, et al. Colorectal cancer: Mutations in a signalling pathway. Nature. 2005; 436:792. [PubMed: 16094359]

Qin JZ, Kamarashev J, Zhang CL, Dummer R, Burg G, Dobbeling U. Constitutive and interleukin-7and interleukin-15-stimulated DNA binding of stat and novel factors in cutaneous t cell lymphoma cells. J Invest Dermatol. 2001; 117:583-589. [PubMed: 11564163] 
Raz R, Durbin JE, Levy DE. Acute phase response factor and additional members of the interferonstimulated gene factor 3 family integrate diverse signals from cytokines, interferons, and growth factors. J Biol Chem. 1994; 269:24391-24395. [PubMed: 7523373]

Rolling C, Treton D, Pellegrini S, Galanaud P, Richard Y. I14 and il13 receptors share the gamma c chain and activate stat6, stat3 and stat5 proteins in normal human b cells. FEBS Lett. 1996; 393:53-56. [PubMed: 8804422]

Rosenthal E. The \$2.7 trillion medical bill. The New York Times. Jun 1.2013 2013.

Rubie C, Frick VO, Pfeil S, Wagner M, Kollmar O, Kopp B, et al. Correlation of il-8 with induction, progression and metastatic potential of colorectal cancer. World J Gastroenterol. 2007; 13:49965002. [PubMed: 17854143]

Rubin DT, Huo D, Kinnucan JA, Sedrak MS, McCullom NE, Bunnag AP, et al. Inflammation is an independent risk factor for colonic neoplasia in patients with ulcerative colitis: A case-control study. Clin Gastroenterol Hepatol. 2013; 11:1601-1608. [PubMed: 23872237]

Sato T, McCue P, Masuoka K, Salwen S, Lattime EC, Mastrangelo MJ, et al. Interleukin 10 production by human melanoma. Clin Cancer Res. 1996; 2:1383-1390. [PubMed: 9816311]

Singh S, Singh AP, Sharma B, Owen LB, Singh RK. Cxc18 and its cognate receptors in melanoma progression and metastasis. Future Oncol. 2010; 6:111-116. [PubMed: 20021212]

Sinsky CA, Dugdale DC. Medicare payment for cognitive vs procedural care: Minding the gap. JAMA Intern Med. 2013; 173:1733-1737. [PubMed: 23939411]

Sozzani S, Rieppi M, Locati M, Zhou D, Bussolino F, Proost P, et al. Synergism between platelet activating factor and c-c chemokines for arachidonate release in human monocytes. Biochem Biophys Res Commun. 1994; 199:761-766. [PubMed: 7510961]

Taub DD, Proost P, Murphy WJ, Anver M, Longo DL, van Damme J, et al. Monocyte chemotactic protein-1 (mcp-1), -2, and -3 are chemotactic for human t lymphocytes. J Clin Invest. 1995; 95:1370-1376. [PubMed: 7883984]

Todorovic-Rakovic N, Milovanovic J. Interleukin-8 in breast cancer progression. J Interferon Cytokine Res. 2013; 33:563-570. [PubMed: 23697558]

Uguccioni M, D'Apuzzo M, Loetscher M, Dewald B, Baggiolini M. Actions of the chemotactic cytokines mcp-1, mcp-2, mcp-3, rantes, mip-1 alpha and mip-1 beta on human monocytes. Eur J Immunol. 1995; 25:64-68. [PubMed: 7531149]

van der Plas DC, Smiers F, Pouwels K, Hoefsloot LH, Lowenberg B, Touw IP. Interleukin-7 signaling in human b cell precursor acute lymphoblastic leukemia cells and murine baf3 cells involves activation of stat 1 and stat5 mediated via the interleukin-7 receptor alpha chain. Leukemia. 1996; 10:1317-1325. [PubMed: 8709637]

Vollger LW, Uittenbogaart CH. Interleukin-7 promotes the generation of phenotypically mature cd45ra positive human thymocytes in vitro. Cytokine. 1993; 5:157-168. [PubMed: 8334229]

Waugh DJ, Wilson C. The interleukin-8 pathway in cancer. Clin Cancer Res. 2008; 14:6735-6741. [PubMed: 18980965]

Wetzel K, Menten P, Opdenakker G, Van Damme J, Grone HJ, Giese N, et al. Transduction of human mcp-3 by a parvoviral vector induces leukocyte infiltration and reduces growth of human cervical carcinoma cell xenografts. J Gene Med. 2001; 3:326-337. [PubMed: 11529662]

Wild N, Andres H, Rollinger W, Krause F, Dilba P, Tacke M, et al. A combination of serum markers for the early detection of colorectal cancer. Clin Cancer Res. 2010; 16:6111-6121. [PubMed: 20798228]

Xu LL, McVicar DW, Ben-Baruch A, Kuhns DB, Johnston J, Oppenheim JJ, et al. Monocyte chemotactic protein-3 (mcp3) interacts with multiple leukocyte receptors: Binding and signaling of mcp3 through shared as well as unique receptors on monocytes and neutrophils. Eur J Immunol. 1995; 25:2612-2617. [PubMed: 7589134]

Yuan Y. Multiple imputation using sas software. Journal of Statistical Software. 2011; 45

Zauber AG, Winawer SJ, O'Brien MJ, Lansdorp-Vogelaar I, van Ballegooijen M, Hankey BF, et al. Colonoscopic polypectomy and long-term prevention of colorectal-cancer deaths. N Engl J Med. 2012; 366:687-696. [PubMed: 22356322] 

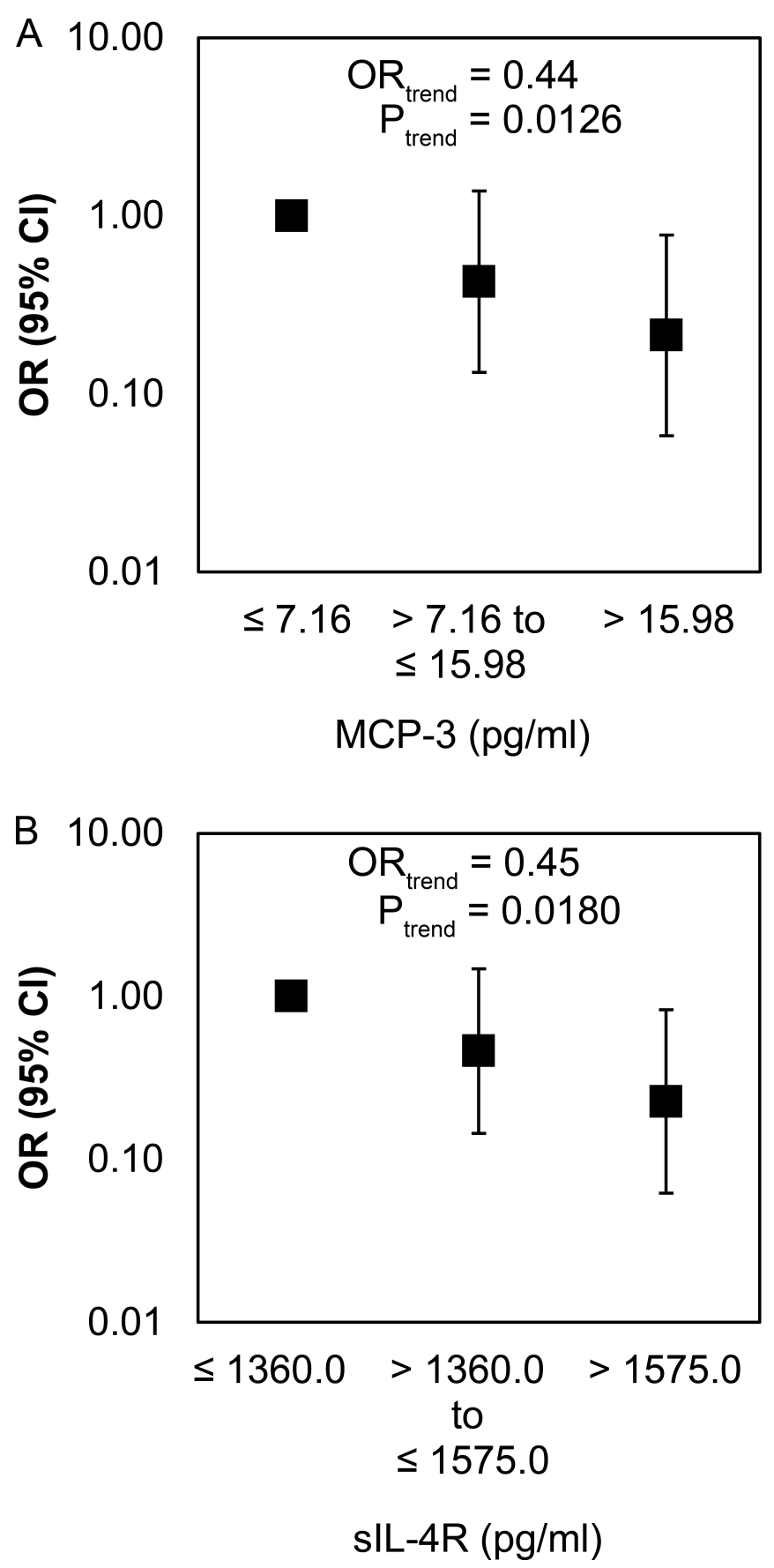

Figure 1. The $\mathrm{OR}$ of having $\geq 3$ polyps relative to no polyps is negatively associated with serum MCP-3 (A) and SIL-4R (B)

A, Compared to males with a serum MCP-3 concentration $\leq 7.16 \mathrm{pg} / \mathrm{ml}$, males with a serum MCP-3 concentration $>15.98 \mathrm{pg} / \mathrm{ml}$ are 0.21 times less likely to have $\geq 3$ polyps $(\mathrm{p}=0.0196)$ relative to no polyps. In addition for each increase in serum MCP-3 tertile, a man is 0.44 times less likely to have $\geq 3$ polyps than no polyps $(\mathrm{p}=0.0126)$. Reference group $=$ males with MCP-3 concentrations in the lowest tertile. B, Compared to males with a serum sIL-4R concentration $\leq 1360.0 \mathrm{pg} / \mathrm{ml}$, males with a serum sIL-4R concentration $>1575.0 \mathrm{pg} / \mathrm{ml}$ are 0.22 times less likely to have $\geq 3$ polyps $(\mathrm{p}=0.0246$ ) relative to no polyps. In addition for 
each increase in serum sIL-4R tertile, a man is 0.45 times less likely to have $\geq 3$ polyps than no polyps $(\mathrm{p}=0.0180)$. Reference group $=$ males with sIL-4R concentrations in the lowest tertile. The models were adjusted for age and smoking status (ever/never). 

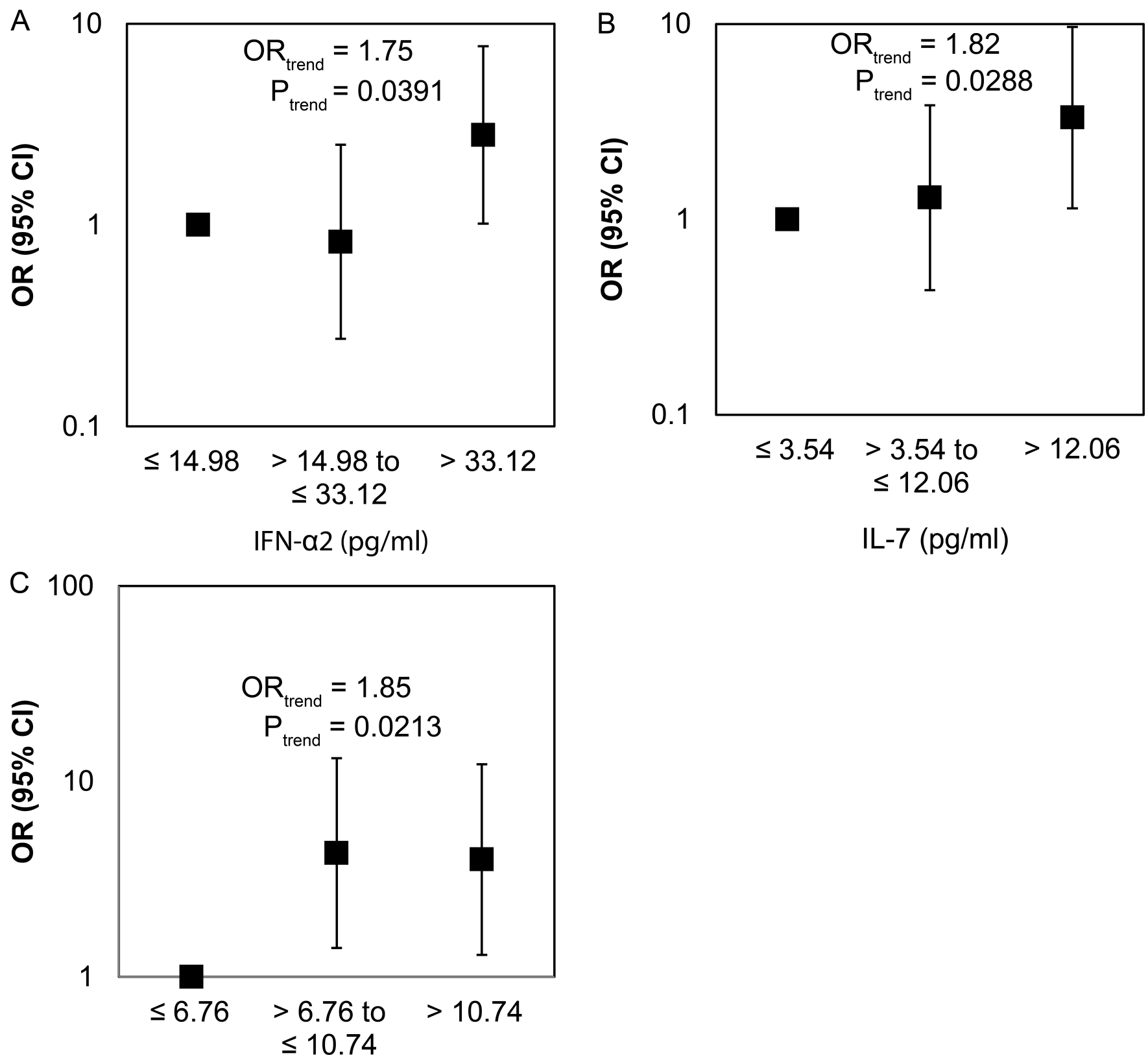

IL-7 (pg/ml)

\section{IL-8 (pg/ml)}

Figure 2. Serum IFN-a2, IL-8 and IL-7 concentrations are associated with the presence of adenomas

A, Compared to males with a serum IFN-a2 concentration $\leq 14.98 \mathrm{pg} / \mathrm{ml}$, males with a serum IFN-a 2 concentration $>33.12 \mathrm{pg} / \mathrm{ml}$ are 2.8 times more likely to have an adenoma ( $\mathrm{p}=0.0468$ ) relative to no polyps. Further, for each increase in serum IFN-a2 tertile, an individual is 1.75 times more likely to have an adenoma than no polyp ( $\mathrm{p}=0.0391)$.

Reference group $=$ males with IFN-a2 concentrations in the lowest tertile. $\mathrm{B}$, Compared to males with a serum IL-7 concentration $\leq 3.54 \mathrm{pg} / \mathrm{ml}$, males with a serum IL-7 concentration $>12.06 \mathrm{pg} / \mathrm{ml}$ are 3.3 times more likely to have an adenoma $(\mathrm{p}=0.0277)$ relative to no 
polyps. Further, for each increase in serum IL-7 tertile, an individual is 1.82 times more likely to have an adenoma than no polyp ( $\mathrm{p}=0.0288)$. Reference group = males with IL-7 concentrations in the lowest tertile. C, Compared to males with a serum IL-8 concentration $\leq$ $6.76 \mathrm{pg} / \mathrm{ml}$, males with a serum IL- 8 concentration $>10.74 \mathrm{pg} / \mathrm{ml}$ are 4.0 times more likely to have an adenoma ( $\mathrm{p}=0.0158$ ) relative to no polyps. Further, for each increase in serum IL-8 tertile, an individual is 1.85 times more likely to have an adenoma than no polyp $(\mathrm{p}=0.0213)$. Reference group $=$ males with IL- 8 concentrations in the lowest tertile. All models were adjusted for age and smoking status (ever/never). 
Table 1

\begin{tabular}{|c|c|c|c|c|}
\hline \multirow{6}{*}{ 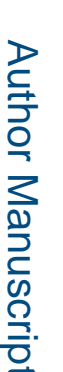 } & \multicolumn{4}{|c|}{ Participant $^{\dagger}$ characteristics $^{\dagger}$} \\
\hline & & Age (years) & BMI $\left(\mathbf{k g} / \mathbf{m}^{2}\right)$ & Waist Circumference (inches) \\
\hline & No Polyps $n=69$ & $57(48-65)$ & $28.4(21.7-39.1)$ & $40.1(30.0-55.0)$ \\
\hline & Any Polyps $n=57$ & $57(50-65)$ & $31.3(19.2-45.6)$ & $42.9(29.8-57.5)$ \\
\hline & $\geq 3$ Polyps $n=23$ & $57(50-65)$ & $32.5(19.2-45.6)$ & $43.7(31.8-57.5)$ \\
\hline & Adenoma $n=37$ & $57(50-65)$ & $32.3(19.2-45.6)$ & $43.6(29.8-57.5)$ \\
\hline
\end{tabular}

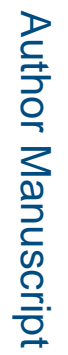

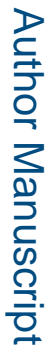

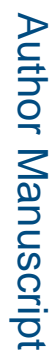

Eur J Cancer Prev. Author manuscript; available in PMC 2017 May 01. 


\section{Table 2}

Cytokine concentrations

\begin{tabular}{|c|c|c|c|c|}
\hline & No Polyps n=69 & Any Polyps n=57 & $\mathbf{3}$ Polyps n=23 & Adenoma n=37 \\
\hline IFN-a2 $(\mathrm{pg} / \mathrm{ml})$ & $18.1(1.9-445.0)$ & $28.1(0.0-211.0)$ & $28.1(5.2-94.2)$ & $33.8(0.0-205.0)$ \\
\hline IL-7 $(\mathrm{pg} / \mathrm{ml})$ & $6.0(0.0-136.0)$ & $7.4(0.0-84.3)$ & $5.7(0.0-35.8)$ & $9.8(0.0-57.9)$ \\
\hline IL-8 $(\mathrm{pg} / \mathrm{ml})$ & $7.1(1.5-68.8)$ & $9.1(0.8-78.0)$ & $8.0(0.8-19.4)$ & $9.8(0.8-44.1)$ \\
\hline IL-10 $(\mathrm{pg} / \mathrm{ml})$ & $5.5(0.0-166.0)$ & $6.4(0.0-175.0)$ & $3.7(0.0-81.3)$ & $10.2(0.0-106.0)$ \\
\hline sIL-4R $(\mathrm{pg} / \mathrm{ml})$ & $1475.0(825.0-2965.0)$ & $1415.0(840.0-2380.0)$ & $1345.0(1090.0-2105.0)$ & $1415.0(840.0-2380.0)$ \\
\hline MCP-3 (pg/ml) & $11.6(0.0-372.0)$ & $8.3(0.0-249.0)$ & $6.8(0.0-58.6)$ & $8.3(0.0-221.0)$ \\
\hline MDC $(\mathrm{pg} / \mathrm{ml})$ & $963.0(449.0-2108.0)$ & $1171.0(128.0-2663.0)$ & $1287.0(546.0-2663.0)$ & $1082.0(615.0-2663.0)$ \\
\hline
\end{tabular}

${ }_{\text {Reported as median (range) }}$ 


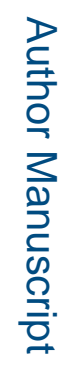

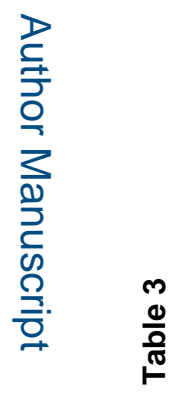

\begin{tabular}{|c|c|c|c|c|c|c|c|c|c|c|}
\hline 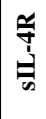 & 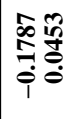 & 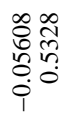 & 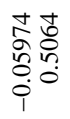 & 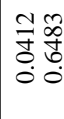 & 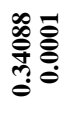 & $\begin{array}{l}\tilde{N}= \\
\sigma= \\
\stackrel{\sigma}{0}=0\end{array}$ & 资商 & 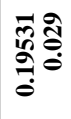 & 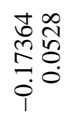 & \\
\hline $\mathscr{O}$ & 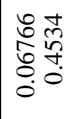 & 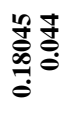 & 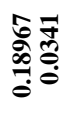 & 递充 & $\begin{array}{l}n= \\
\tilde{\infty} \\
\\
0 \\
0 \\
0\end{array}$ & 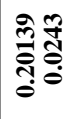 & 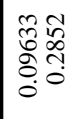 & 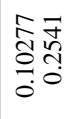 & & $\begin{array}{ll}0 & 0 \\
0 & 0 \\
0 & 0 \\
0 & 0 \\
0 & 0\end{array}$ \\
\hline$\frac{\tilde{8}}{\tilde{z}}$ & 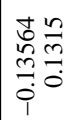 & $\begin{array}{l}m \\
\tilde{y}= \\
0 \\
0 \\
0 \\
0\end{array}$ & 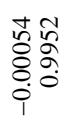 & 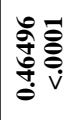 & 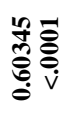 & 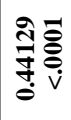 & 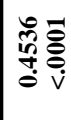 & & 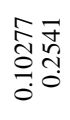 & 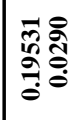 \\
\hline$\stackrel{1}{3}$ & 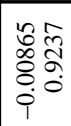 & 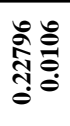 & $\begin{array}{l}\infty \\
\sigma^{2} \\
\overbrace{0}^{\circ}=\end{array}$ & 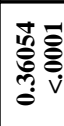 & 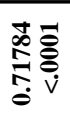 & 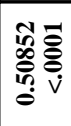 & & 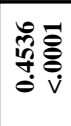 & 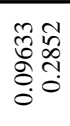 & 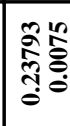 \\
\hline$\infty$ & 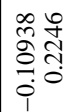 & 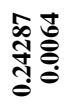 & 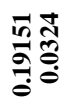 & 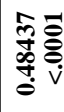 & 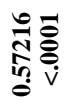 & & 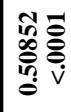 & 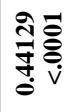 & 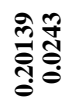 & 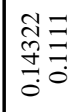 \\
\hline
\end{tabular}

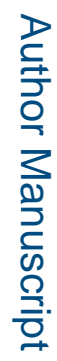

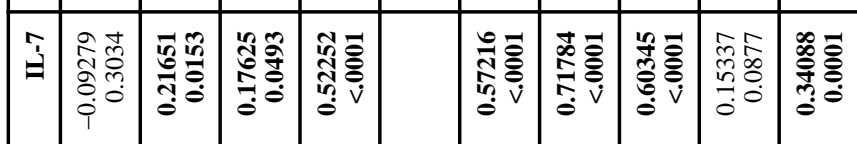

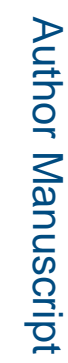

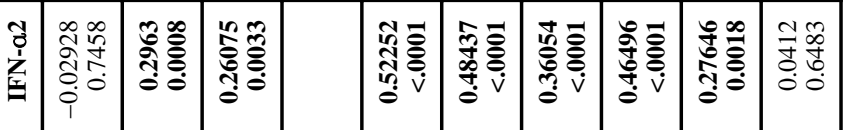

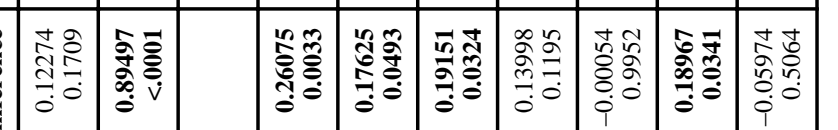

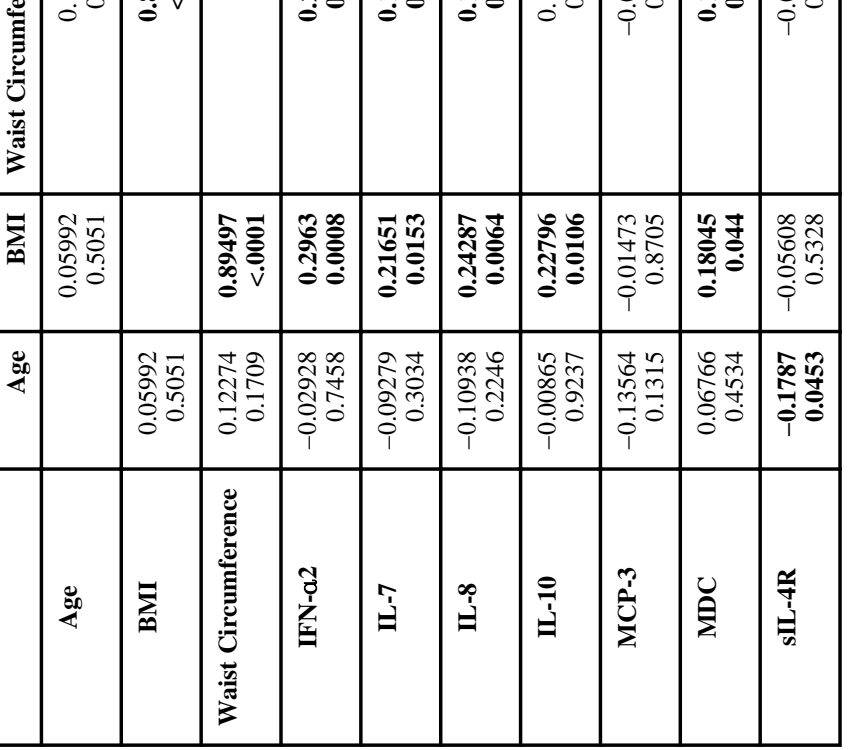


Table 4

Association of cytokines with having $\geq 3$ polyps relative to no polyps

\begin{tabular}{|c|c|c|c|c|}
\hline & No Polyp n & $\geq 3$ Polyps n & OR $(95 \% \mathrm{CI})$ & Trend $\mathrm{OR}(\mathrm{P}$ trend $)$ \\
\hline \multicolumn{5}{|l|}{ MCP-3 (pg/ml) } \\
\hline$\leq 7.2$ & 19 & 13 & 1 & \\
\hline$>7.2$ to $\leq 16.0$ & 24 & 6 & $0.43(0.13-1.38)$ & 0.44 \\
\hline$>16.0$ & 26 & 4 & $0.21(0.06-0.78)$ & $(0.0126)$ \\
\hline \multicolumn{5}{|l|}{ sIL-4R (pg/ml) } \\
\hline$\leq 1360.0$ & 20 & 12 & 1 & \\
\hline$>1360.0$ to $\leq 1575.0$ & 20 & 7 & $0.46(0.14-1.48)$ & 0.45 \\
\hline$>1575.0$ & 29 & 4 & $0.23(0.06-0.83)$ & $(0.018)$ \\
\hline \multicolumn{5}{|l|}{$\mathrm{MDC}(\mathrm{pg} / \mathrm{ml})$} \\
\hline$\leq 889.5$ & 27 & 6 & 1 & \\
\hline$>889.5$ to $\leq 1224.5$ & 26 & 4 & $0.68(0.17-2.72)$ & 1.86 \\
\hline$>1224.5$ & 16 & 13 & $3.14(0.95-10.37)$ & $(0.0555)$ \\
\hline \multicolumn{5}{|l|}{ IFN-a2 (pg/ml) } \\
\hline$\leq 15.0$ & 25 & 6 & 1 & \\
\hline$>15.0$ to $\leq 33.1$ & 26 & 7 & $1.06(0.31-3.67)$ & 1.37 \\
\hline$>33.1$ & 18 & 10 & $1.95(0.58-6.59)$ & $(0.3104)$ \\
\hline \multicolumn{5}{|l|}{$\mathrm{IL}-7$ (pg/ml) } \\
\hline$\leq 3.5$ & 24 & 9 & 1 & \\
\hline$>3.5$ to $\leq 12.1$ & 26 & 8 & $0.81(0.26-2.49)$ & 0.95 \\
\hline$>12.1$ & 19 & 6 & $0.95(0.28-3.24)$ & $(0.8735)$ \\
\hline \multicolumn{5}{|l|}{ IL-8 (pg/ml) } \\
\hline$\leq 6.8$ & 30 & 6 & 1 & \\
\hline$>6.8$ to $\leq 10.7$ & 19 & 10 & $2.66(0.81-8.75)$ & 1.35 \\
\hline$>10.7$ & 20 & 7 & $1.85(0.53-6.48)$ & $(0.3272)$ \\
\hline \multicolumn{5}{|l|}{$\mathrm{IL}-10(\mathrm{pg} / \mathrm{ml})$} \\
\hline$\leq 3.0$ & 26 & 8 & 1 & \\
\hline$>3.0$ to $\leq 11.5$ & 22 & 9 & $1.41(0.45-4.38)$ & 1.03 \\
\hline$>11.5$ & 21 & 6 & $1.09(0.31-3.78)$ & $(0.9002)$ \\
\hline
\end{tabular}

Note: Model is adjusted for age and ever/never smoked. 
Table 5

Association of cytokines with the presence of a tubular adenoma relative to no polyps

\begin{tabular}{|c|c|c|c|c|}
\hline & No Polyp n & Adenoma n & OR $(95 \% \mathrm{CI})$ & Trend $\mathrm{OR}(\mathrm{P}$ trend $)$ \\
\hline \multicolumn{5}{|l|}{ IFN-a2 (pg/ml) } \\
\hline$\leq 15.0$ & 25 & 9 & 1 & \\
\hline$>15.0$ to $\leq 33.1$ & 26 & 8 & $0.82(0.27-2.50)$ & 1.75 \\
\hline$>33.1$ & 18 & 20 & $2.80(1.01-7.73)$ & $(0.0391)$ \\
\hline \multicolumn{5}{|l|}{$\mathrm{IL}-7$ (pg/ml) } \\
\hline$\leq 3.5$ & 24 & 8 & 1 & \\
\hline$>3.5$ to $\leq 12.1$ & 26 & 11 & $1.29(0.43-3.84)$ & 1.82 \\
\hline$>12.1$ & 19 & 18 & $3.32(1.14-9.66)$ & $(0.0288)$ \\
\hline \multicolumn{5}{|l|}{ IL-8 (pg/ml) } \\
\hline$\leq 6.8$ & 30 & 6 & 1 & \\
\hline$>6.8$ to $\leq 10.7$ & 19 & 16 & $4.29(1.41-13.13)$ & 1.85 \\
\hline$>10.7$ & 20 & 15 & $3.98(1.30-12.24)$ & $(0.0213)$ \\
\hline \multicolumn{5}{|l|}{ IL-10 (pg/ml) } \\
\hline$\leq 3.0$ & 26 & 9 & 1 & \\
\hline$>3.0$ to $\leq 11.5$ & 22 & 12 & $1.65(0.58-4.74)$ & 1.6 \\
\hline$>11.5$ & 21 & 16 & $2.63(0.927-7.47)$ & $(0.083)$ \\
\hline \multicolumn{5}{|l|}{ sIL-4R (pg/ml) } \\
\hline$\leq 1360.0$ & 20 & 14 & 1 & \\
\hline$>1360.0$ to $\leq 1575.0$ & 20 & 16 & $0.98(0.37-2.57)$ & 0.61 \\
\hline$>1575.0$ & 29 & 7 & $0.35(0.12-1.04)$ & $(0.0653)$ \\
\hline \multicolumn{5}{|l|}{ MCP-3 (pg/ml) } \\
\hline$\leq 7.2$ & 19 & 15 & 1 & \\
\hline$>7.2$ to $\leq 16.0$ & 24 & 12 & $0.72(0.27-1.94)$ & 0.68 \\
\hline$>16.0$ & 26 & 10 & $0.48(0.17-1.32)$ & $(0.1362)$ \\
\hline \multicolumn{5}{|l|}{$\mathrm{MDC}(\mathrm{pg} / \mathrm{ml})$} \\
\hline$\leq 889.5$ & 27 & 12 & 1 & \\
\hline$>889.5$ to $\leq 1224.5$ & 26 & 9 & $0.76(0.27-2.14)$ & 1.4 \\
\hline$>1224.5$ & 16 & 16 & $2.00(0.73-5.50)$ & $(0.2119)$ \\
\hline
\end{tabular}

Note: Model is adjusted for age and ever/never smoked. 